\title{
A Conceptual Study on Hospital Information System in Public Hospital of Bangladesh: Electronic Medical Record and Clinical Information System Perspective
}

\author{
Md. Mahmudul Haque ${ }^{1}$, Saim Kayadibi ${ }^{2}$, Khondakar S. Rafsanjani ${ }^{3}$ \& Mabruk Billah $^{3}$ \\ ${ }^{1}$ Department of Finance, The Global University of Islamic Finance (INCEIF), Kualalumpur, Malaysia \\ ${ }^{2}$ Department of Economics, International Islamic University Malaysia, Kualalumpur, Malaysia \\ ${ }^{3}$ Department of Business Administration, International Islamic University Malaysia, Kualalumpur, Malaysia \\ Correspondence: Md. Mahmudul Haque, Department of Finance, The Global University of Islamic Finance \\ (INCEIF), Kualalumpur, Malaysia. Tel: 60-14-930-8451.E-mail: tasnim128@yahoo.com
}

Received: August 1, 2013 Accepted: October 4, 2013 Online Published: November 29, 2013

doi:10.5539/ass.v9n17p180 URL: http://dx.doi.org/10.5539/ass.v9n17p180

\begin{abstract}
The empirical data is used in organizations all over the world which require the integration of some informational systems like Electronic Medical Record (EMR) and Clinical Information System (CIS); these concepts will discover with new form of Bangladeshi public hospital's improvement in Information Technology (IT) sector. The objective of this conceptual paper is to review critically and identify the gaps in current literature aligning with Hospital Information System (HIS) and Electronic Medical Record (EMR), building relationship between EMR and CIS in terms of Bangladeshi public hospital; towards hospital's effectiveness of service operator when public hospital plays an important role to keep the patients data. The proposed conceptual framework assists HIS providers to understand how EMR and CIS can contribute to improve the hospitals patient database. More over the paper presents an analysis in various aspects of EMR and CIS complying with a conceptual framework which can attract the researchers in Hospital information System field and public hospital management field for the better presences of information technology for the patients. Hospital Information System (HIS) is essential in hospitals especially which deals with high-quality healthcare treatments. HIS helps to improve patients care services. Thus, the Bangladesh Government has not introduced any kind of HIS for public hospitals of Bangladesh. Moreover, there is no study on HIS implementation in Bangladeshi public hospital.
\end{abstract}

Keywords: hospital information system, electronic medical record, clinical information system, Bangladesh, patient, information technology

\section{Introduction}

In this present world, the existence use of technology plays vital role to enhance the economic and social life (O’Leary \& O’Leary, 2005). Nowadays healthcare including public hospital has a main fact which is Information technology (IT). That is why patient care service is improving through the information technology. The Bangladeshi healthcare sector is basically divided into three providers and they are public, private, and Non-Governmental Organizations (NGOs) (Annual Report, 2009). The public healthcare sector like the government hospitals are run in a subtle system which are more complex than the other healthcare providers. The public hospitals provide healthcare facilities ranging from the rich to poor patients, whereas the private hospitals mainly focus on the rich category patients as they are the only one who can afford the expensive medical bills. Hence most public hospitals are mostly overpopulated with patients and their relatives and this usually creates uncomfortable environment in and around the hospital. This can also lead to inefficient system implementation which creates time lag, means that patients usually wait for longer hours to get their treatment. When all these factors are combined it clearly depicts that the public sector healthcare is of lower level. Also, the Ministry of Health shows rising number of negligence cases reported between 2000 and 2008 (Annual report, 2009). Therefore, Hospital Information System (HIS) is believed to enhance the quality of healthcare services.

The main purpose of this research is to know and scrutinizing the actual ongoing information system in public hospital in Bangladesh. The examination wills be emphasized on two aspect Electronic Medical Record (EMR) 
and Clinical information System (CIS). There is a significant research gap exist in building up the model of EMR and CIS in the Hospital Information system (HIS) of public Hospital. On the other hand, in any developing country like Bangladesh, empirical research is incomplete and so the contribution of new knowledge in this area is essential. The present research has gathered previous empirical research on hospital information system which ultimately helped the researchers to draw a conceptual framework line for further empirical test related to Hospital information system in public hospital industry of Bangladesh.

The paper includes three steps to explain the subject matter, those are followings. First, find out the existing information about the subject matter concerning the Electronic Medical Record (EMR) and Clinical Information System (CIS) construct in the area of Hospital Information System (HIS). Secondly, The development of theoretical mechanisms combining with EMR attributes and CIS is constructed to a theory to do further empirical test to know that how patient and operator of hospital are eager to use this model in public hospital of Bangladesh to increase the productivity of hospital. Finally, the practical implications are discussed in this research which may become useful contribution to the hospital industry controllers and also to the literatures research which based on hospital information system.

This research is important because the study of hospital information system has become essential and need for the hospital operators, new implication of storing the information can be applied by them to find out the patients and hospital service holders' ultimate needs in this particular sector.

\section{Literature Review}

\subsection{Background of HIS in Public Hospital of Bangladesh}

The civil society group (Bangladesh Health Watch) makes for some shocking discloses about The State of Health in Bangladesh report in 2007, this report is talking about on human resources in the health care sector, the gloomy facts of the story are that Bangladesh is still running a surprising scarcity of over 60,000 doctors (currently figure 31,000 physicians), and also have a shortage of almost 140,000 nurses (Mahmood, 2012). It is because, statistical information reveals that only $25 \%$ of the population is used publicly funded health care system every day, on an average, 1,432 patients come to the outdoor and 450 to the emergency units of the hospital, while 184 patients are admitted to the indoor for treatment. From this statistical approach approximately 44300 patients come to the outdoor and 13000 people get the emergency units of the overall performance in all of the public hospital of Bangladesh. On the other hand, this country has a keen lack of medical technologists and associated health professionals and these are physiotherapists, laboratory assistants, x-ray technicians, etc. Approximately there are 25 departments, 48 units, and 45 wards in Dhaka Medical College Hospital. Even though this research has considered this information for a single public hospital but it can represents other hospital as well. (Akter \& Islam, 2006; Ministry of Health and Family Welfare, 2003).

Furthermore, the patients of the public hospital of Bangladesh also face technical irregularity. The mainly observable crisis is lack of time. For this reason many patients do not get enough time after admission in the hospital (Akter \& Islam, 2006; Chowdhury et al., 2006) depicts that $71 \%$ of the patients mentioned that they had to wait for the doctors on an average 78 minutes. This situation could be worsening during the monsoon season and other recurrent natural disasters, the already meager services for the urban and rural population were severely disrupted. (Lopez, 1988).

\subsection{Hospital Information System (HIS)}

Schreiweis \& Heilbronn, (2010) mentioned that at the present world, hospital information systems (HIS) are a vital point of patient care. HIS provides best information, to the right people and the right place. The world has shortage of technical support in medical care. However, hospital information systems (HIS) are the solution of patient care, helps to make proper decisions (Patrice et al., 1995; Andre \& Vimla, 2004). The computer has become essential to health care system, driven in part by stimulated growth of digital applications and communication technologies over the last two decades. That is why HIS system is the new development of health care system (Chamorro, 2001). According to Heller (1995) Hospital information Systems (HIS) is very essential for technological decade. HIS provides great efforts to Medical Information System (MIS). Nowadays, HIS system is the new system which is spreading throughout the world. So in HIS system, there is one model which is called Electronic Health Records (EHRs). HIS model has benefit to minimize the cost (Miller \& West, 2007). In HIS system, Electronic Medical Records (EMRs) and Clinical Information System (CIS) which creates a new model for improving patient safety, evolving coordination of care, and clinical decision making (Catherine et al., 2009). To concern HIS, there are two model introduced under the HIS which are electronic Medical records (EMRs), and Clinical Information System (CIS) where it would be helpful for patient care, patient safety (Robert et al., 2009). 


\section{Conceptual Framework Development}

\subsection{Electronic Medical Record (EMR)}

EMR system helps through electronic proposed information and at the same time it omits the use of the paper based system. It is used to make review of the practitioner responses, discharge summaries, and consultants' letters. The referral data and review were examined under this. The conflict between primary and secondary care has been inputted, though the diagnosis and procedural data have been found to improve the quality documents of primary care. The reliability of the data is about eighteen studies which are used in national statistics or survey (Eames, 1995; Department of General Practice. GPASS data validation report, 1995; Oxfordshire, 2000; Oxford: Primary Care Information Services (PRIMIS), 2000; Thiru et al., 1999; Nazareth et al., 1993; Pearson et al., 1996; Whitelaw et al., 1996; Kaye et al., 2000; Hansell et al., 1999; Hollowell, 1997; Boydell et al., 1995; Hassey et al., 2001; Meal et al., 2000; Martin, 1995; Njalsson, 1992; Simpson et al., 2001; Grimsmo et al., 2001).

It is believed that this is the orderly diagnosis to evaluate the dignified quality of data in primary care. After 1995 the use of EMR has increased. The essential publications provide framework which is classified and categorized. The patient identification and diagnostic data were the main point of preferable studies and surveys. It will be best applied for an environment vital influence comes from external forces (for example, leap of scientifically development). The shortage of interrupted in studies passivity and inability of in the study environment of researchers. The appraisal of data quality has favored the selection of practices that embrace technology and was the likely reason for purposive sampling in many studies. Consequently, the EPR quality reported in the literature is likely to be an overestimate of the general picture (Thiru et al., 2003)

The elements of the EPR are investigated (numerator) and the components of the reference standard is used to appraise its quality (denominator) where often not clearly defined within the literature (for instance, diagnostic code/diagnostic criteria). Once there was trial to define but found inconsistency between studies. This make the comparisons risky and meta-analytical interpretation of results impossible which may be a reflection of the immaturity of the discipline which is more standardized approaches have not yet evolved (Thiru et al., 2003). Many barriers to and facilitators of EMR implementation have been identified. However, there is a lack of evidence about what helps to facilitate information technology adoption among health care providers (Gagnon et al.; Cochrane Database System Rev 2009).

Little is known about how primary health care providers use the specific features of EMRs (Simon et al., 2007) and few studies explore the longitudinal aspects of early EMR implementation and later adoption in primary health care (El-Kareh et al., 2009; Kaelber et al., 2005; Gadd et al., 2001). The prim object of the analysis is to identify themes regarding the ongoing EMR use is quite common among the practice sites. These practices moves beyond the implementation stage and is focused on the use of the EMR. Factors that delayed and provoked continuing use is emerged. The hindrance usage includes (1) information technology challenges such as learning to use the EMR, electronic connectivity, and scanning; and (2) variability in EMR use. Two factors motivate the ongoing usage: (1) The improved efficiency in providing patient care, and (2) the actual competency with computers and the EMR System (Amanda et al., 2012). Computer skills have been counted as lack from the previous studies (Simon et al., 2007; Gans et al., 2005; Boonstra et al., 2010; Simon et al., 2008). The struggle has done by the previous study was struggling to implement the EMR (Terry et al., 2009). The physicians and nurses are less satisfied to use the patient records as scanned images compare with the use of EMR (Lium et al., 2006).

\subsection{Clinical Information System (CIS)}

According to (Kleinke, 2005) The U.S. health care system is continuing to adopt failed information technologies which create deficiently impacts economic problems. So now a day there is clinical information system (CIS) which is enhancing day by day. Health care of people needs clinical information system (CIS) which is involved in health information system and its terms are very efficient for present world to promote the HIS system (Detmer \& Steen, 1996). It is because the benefits the using this informational technologies for health care work can be fruitful to reduce excessive work load (Detmer \& Steen, 1996).

On the other hand according to (Kleinke, 1998), proper patient care, patient safety, and accurate information of health care can be possible using CIS. According to (Greene et al., 2012), there are two systems which can be used to data documentation and investigation; firstly, the "rapid learning health system" posited as a conceptual strategy and its process begins with problem reorganization and characterization and data to identify gaps in patient experience, excellence justification, and efficiency and then search for proof-based resolution. Secondly, to inducement the transformation, it means to pull out recent developments in health information technology and 
a growing health data substructure to access and apply evidence in real time, while simultaneously drawing knowledge from real-world care delivery processes to promote innovation and health system change based on severe, generalized research (Greene et al., 2012).

The CIS design work and option of safety improvements each involved primary care clinicians, content experts, information technology personnel, researchers, and clinic staff to develop core components for the entire system and elements that could vary locally. The opioid prescribing initiative combined design and prototyping into an intensive week-long workshop where representatives from across the organization refined new care processes, developed standardized patient education materials, and identified specialty care consultants to help manage complex cases. This intensive effort, based on east available evidence, allowed all stakeholders iteratively develop and refine the tools and resources needed to improve prescribing safety (Roberts et al., 2001; Nelson et al., 2002). The highest quality, most affordable care provided for just about anything where the main factor is to satisfy the customers. CIS users are quite advance in terms of access and resolve the problems from inherited information from trusted sources. In a health care system competition for consumer's attention will be driven by quality and affordability (Roberts et al., 2001).

Following the precaution of the past literature reviews; this research concentrates more on conceptual framework of Hospital information System (HIS) by using Electronic Medical Record (EMR) and Clinical Information System model. This Hospital Information System framework emphasizes on EMR and CIS. The independent variables are positively related to the consumer's purchases or deal intention using broadband internet service. The diagram framework is given below:

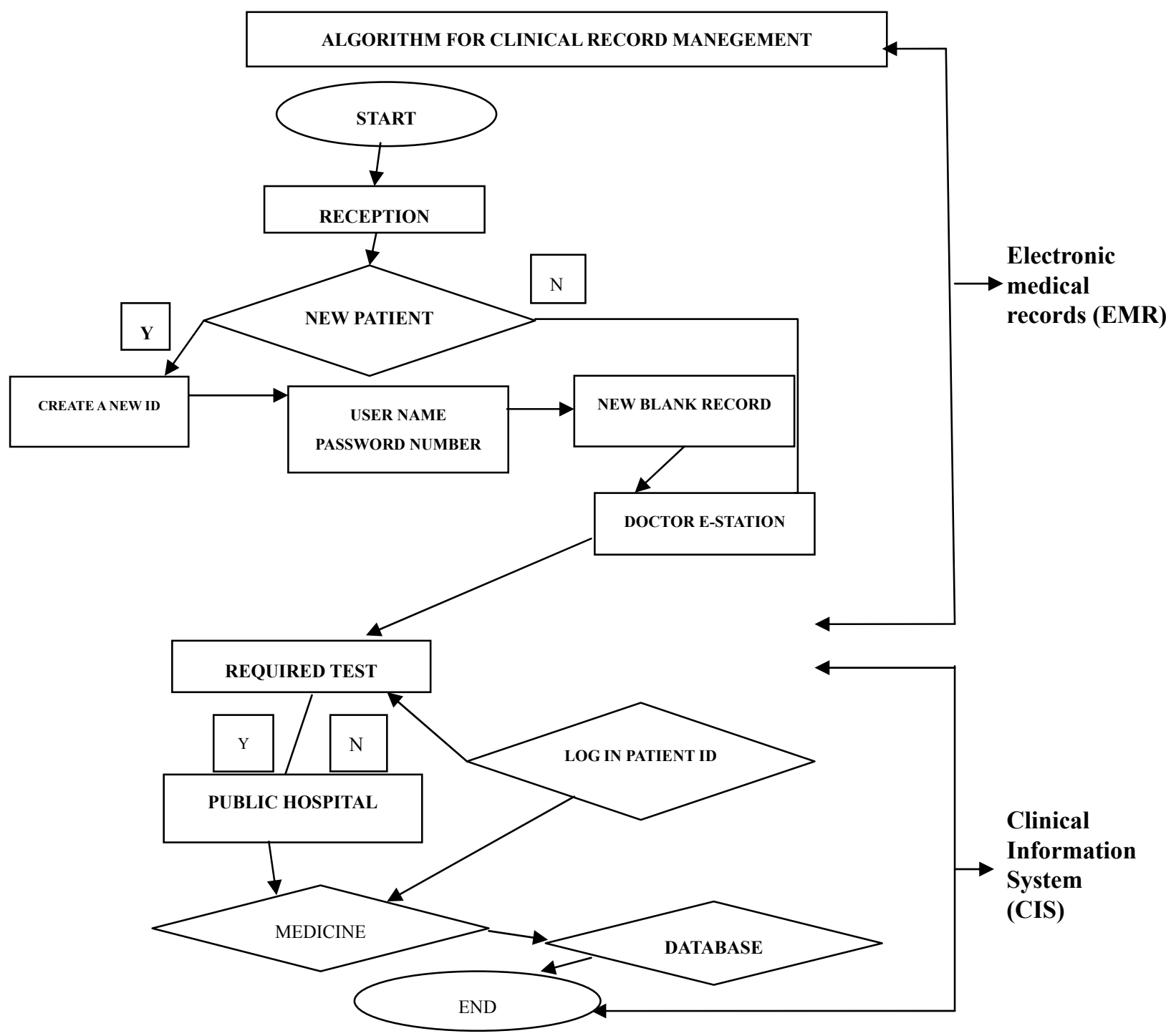

Figure 1. Conceptual framework 
The following proposition researchers can draw which have already highlighted in the conceptual framework:

P1: Electronic Medical Record plays a significant role on Hospital Information System of a medical service provider's service where the new patient plays a mediating variable.

P2: Clinical Information System plays a significant role on Hospital Information System of a medical service provider's service where the new patient plays a mediating variable.

\section{Practical Implication}

At present, research that directly linked the combine concepts of various Hospital Information System models combining with EMR and CIS on understanding public and private hospital information system which has lot of gap between patient and hospital service holder. The need for understanding the integration between historical data and new concepts followed by the discovered new model of hospital information system in Bangladeshi public hospital are essential. This knowledge gap can be filled by this conceptual paper. Until now lot of researchers proposed hospital information systems to understand the relationship among Financial Information System (FIS), Laboratory Information System (LIS), Nursing Information System (NIS), Pharmacy Information System (PIS), Picture Archiving and Communication System (PACS), and Radiology Information System (RIS) but problem raised from Electronic Medical Record (EMR) which can be combine effect on hospital information system which didn't have adequate consideration and the present researchers have continued to raise concerns it. In this study, researchers have elaborated several attributes of hospital information system which may suggesting that there is link between EMR and CIS to maximize their overall service to attract more patient from the society who are intend to go private hospital. This research also suggested that EMR and CIS both have direct and indirect effect on patient and also on hospital itself. To understand the hospital information system of the public hospital in Bangladesh researchers designed to believe that the proposed conceptual model can provides both a theoretical contribution and managerial contribution. The researchers strongly believed foundation of this primary study need to test empirically in future to evaluate the perception of hospital operator and patient as well. The researchers recommend paying specific attention to this issue in further research by the academicians also add value in the Automated Treatment System (ATS) which is the limitation of this study.

\section{Conclusions and Further Recommendations}

This paper has main concept is HIS issues and its link with EMR and CIS. On the other hand, there are several policies for the hospital service holder who is in effort to changes the hospital's overall system through understanding patients demand. What are the items explained above are active in nature which must be noted. Researchers extended that the correlation between these fundamentals be given vigilant thought and consideration if public hospital is desired to attain by this new system. This model will reduce the cost of the hospital and patient as well where public hospital could be more competitive to private hospital of Bangladesh.

On the other hand, it is important to be remembered these interaction on the proposed model do not stand alone; for instance, Electronic medical Record even fulfillment of Clinical information system will not assist all time to satisfy the patient in public hospital because of limitation of this model. Further research empirical research is essential to measure the system proposed in this model empirically to test the relationship so that public hospital industry will get a comprehensive framework to practice in their hospital to sustain economic growth of Bangladesh.

\section{References}

Akter, T., \& Islam, S. (2006). Dhaka Medical College Hospital: A Diagnostic Study.

Amanda, L., Terry, J. B. B., Denomme, M. A. L. B., Thind, M. D. A., \& Stewart, M. (2012). JABFM.

Boonstra, A., \& Broekhuis, M. (2010). Barriers to the acceptance of electronic medical records by physicians from systematic review to taxonomy and interventions. BMC Health Serv. Res., 10, 231. http://dx.doi.org/10.1186/1472-6963-10-231

Chamorro, T. (2001). Computer-based patient record systems. Seminars in Oneology Nursing, 17(1). http://dx.doi.org/10.1053/sonu.2001.20416

Chen, C., Garrido, T., Chock, D., Okawa, G., \& Liang, L. (2009). The Kaiser Permanente Electronic Health Record. Transforming and Streamlining Modalities of Care, Health Affairs, 28(2), 323-333. http://dx.doi.org/10.1377/hlthaff.28.2.323

Chowdhury et al. (2006). Equity in use of home-based or facility-based skilled obstetric care in rural Bangladesh: An observational study. Lancet, 367, 327-332. http://dx.doi.org/10.1016/S0140-6736(06)68070-7

Degoulet, P., Jean, F. C., \& Safranh, C. (1995). The health care professional multimedia workstation: 
Development and integration issue. International Journal of Bio-Medical Computing, 39. http://dx.doi.org/10.1016/0020-7101(94)01089-J

Department of General Practice. (n. d.). GPASS data validation report. Aberdeen: University of Aberdeen. 1995.

Detmer, D. E., \& Steen, E. B. (1996). The computer-based record: patient moving from concept toward reality. International Journal of Bio-Medical Computing, 42. http://dx.doi.org/10.1016/0020-7101(96)01176-2

Eames, M. (1996). The general practice research database: Data quality in measuring morbidity and health: What information can general practice deliver. Hatfield: University of Hertfordshire.

El-Kareh et al. (2009). Trends in primary care clinician perceptions of a new electronic health record. J. Gen. Intern. Med., 24, 464-468. http://dx.doi.org/10.1007/s11606-009-0906-z

Ferrara, F. M. (1998). The standard 'Healthcare Information Systems Architecture' and the DHE middleware. International Journal of Medical Informatics, 52. http://dx.doi.org/10.1016/S1386-5056(97)00123-8

Gadd, C. S., \& Penrod, L. E. (2001). Assessing physician attitudes regarding use of an outpatient EMR: A longitudinal, multi-practice study. Proc. AMIA Symp., 194-198.

Gagnon et al. (2009). Interventions for promoting information and communication technologies adoption in healthcare professionals. Cochrane Database Syst. Rev., (1). http://dx.doi.org/10.1002/14651858.CD006093.pub2

Gans, D., Kralewski, J., Hammons, T., \& Dowd, B. (2005). Medical groups' adoption of electronic health records and information systems. Health Aff., 24, 1323-1333. http://dx.doi.org/10.1377/hlthaff.24.5.1323

Greene, S. M., Reid, R. J., \& Larson, E. B. (2012). Implementing the Learning Health System: From Concept to Action. American Journal of Public Health, 102(6).

Grimsmo, A., Hagman, E., Faiko, E., Matthiessen, L., \& Njalsson, T. (2001). Patients, diagnoses and processes in general practice in the Nordic countries. An attempt to make data from computerised medical records available for comparable statistics. Scand. J. Prim. Health Care Supply, 19, $76-82$. http://dx.doi.org/10.1080/028134301750235277

Hansell, A., Hollowell, J., Nichols, T., McNiece, R., \& Strachan, D. (1999). Use of the general practice research database (GPRD) for respiratory epidemiology: a comparison with the 4th morbidity survey in general practice (MSGP4). Thorax, 54, 413-419. http://dx.doi.org/10.1136/thx.54.5.413

Hassey, A., Gerrett, D., \& Wilson, A. (2001). A survey of validity and utility of electronic patient records in a general practice. BMJ, 322, 1401-1405. http://dx.doi.org/10.1136/bmj.322.7299.1401

Health, Nutrition and Population Sector Program. (2003). Government of Bangladesh, Industry of Health and Family Welfare.

Heller, E. E. (1995). The computer-based patient record vision contrasted with HIS/MIS. International Journal of Bio-Medical Computing, 39. http://dx.doi.org/10.1016/0020-7101(94)01073-A

Hollowell, J. (1997). The general practice research database: quality of morbidity data. Popul. Trends, 37, 36-40.

Kaelber, D., Greco, P., \& Cebul, R. D. (2005). Evaluation of a commercial electronic medical record (EMR) by primary care physicians 5 years after implementation. AMIA Annu. Symp. Proc., 1002.

Kaye, J. A., Derby, L. E., Mar-Melero-Montes, M., Quinn, M., \& Jick, H. (2000). The incidence of breast cancer in the General Practice Research Database compared with national cancer registration data. Br. J. Cancer, 83, 1556-1558. http://dx.doi.org/10.1054/bjoc.2000.1493

Kleinke, J. D. (2005). Dot-Gov: Market Failure and The Creation of a National Health Information Technology System. Health Affairs, 24(5), 1246-1262. http://dx.doi.org/10.1377/hlthaff.24.5.1246

Kushniruk, A. W., \& Patel, V. L. (2004). Cognitive and usability engineering methods for the evaluation of clinical information systems. Journal of Biomedical Informatics, 37

Lium, J. T., Laerum, H., Schulz, T., \& Faxvaag, A. (2006). From the front line, report from a near paperless hospital: mixed reception among health care professionals. J. Am. Med. Inform Assoc., 13, 668-675. http://dx.doi.org/10.1197/jamia.M2108

Lopez, S. (1988). A rural family planning center Courtesy. Bangladesh Ministry of Information.

Mahmood, A. S. (2012). Health Systems in Bangladesh, 1(1), 1.

Martin, R. (1995). The doctor's independent network database: Background and methodology. Pharmaceutical Med., 9, 165-176. 
Meal, A. G., Pringle, M., \& Hammersley, V. (2000). Time changes in new cases of ischemic heart disease in general practice. Fam Pract, 17, 394-400. http://dx.doi.org/10.1093/fampra/17.5.394

Miller, R. H., \& West, C. E. (2007). The Value of Electronic Health Records in Community Health Centers: Policy Implications. Health Affairs, 26(1), 206-214. http://dx.doi.org/10.1377/hlthaff.26.1.206

Miller, R. H., Amato, K. D., Oliva, N., West, C. E., \& Adelson, J. W. (2009). California's Digital Divide: Clinical Information Systems for the Haves and Have-Nots. Health Affairs, 28(2), 505-516. http://dx.doi.org/10.1377/hlthaff.28.2.505

Ministry of Health Bangladesh, annual Report. (2009). Dhaka, Bangladesh.

Nazareth, I., King, M., Haines, A., Rangel, L., \& Myers S. (1993). Accuracy of diagnosis of psychosis on general practice computer system. BMJ, 307, 32-34. http://dx.doi.org/10.1136/bmj.307.6895.32

Nelson et al. (2002). Microsystems in health care: part 1. Learning from high performing front-line clinical units. Jt. Comm. J. Qual. Improv., 28(4), 72-93.

Njalsson, T., \& McAuley, R. G. (1992). On content of practice. An Icelandic multi-centre study, population, practices and contacts. Scand. J. Prim. Health Care, 10, 243-249. http://dx.doi.org/10.3109/02813439209014069

O’Leary, T., \& O’Leary, L. (2005). Computing Essentials. Singapore: McGraw-Hill.

Oxfordshire, M. A. A. G. (2000). Case study: a review of the Oxford shire scheme. Collection of health data from general practice. Oxford: Primary Care Information Services (PRIMIS).

Pearson, N., O’Brien, J., Thomas, H., Ewings, P., Gallier, L., \& Bussey, A. (1996). Collecting morbidity data in general practice: the Somerset morbidity project. BMJ, 312, 1517-1520. http://dx.doi.org/10.1136/bmj.312.7045.1517

PRIMIS. (2000). Nottingham primary care health data project (NPCHDP). Oxford: Primary Care Information Services (PRIMIS).

Roberts, J. M., \& Copeland, K. L. (2001). Clinical web sites are currently dangerous to health. International Journal of Medical Informatics, 62(2/3), 181-187. http://dx.doi.org/10.1016/S1386-5056(01)00162-9

Schreiweis, B., \& Heilbronn. (2010). Modelling the Hospital Information System of the Karolinska University Hospital in Stockhol. University of Heidelberg, Heilbronn University and Karolinska Institutet Graduate Degree Thesis in Medical Informatics.

Simon et al. (2007). Correlates of electronic health record adoption in office practices: A statewide survey. J. Am. Med. Inform Assoc., 14, 110-117. http://dx.doi.org/10.1197/jamia.M2187

Simon et al. (2007). Physicians and electronic health records: A statewide survey. Arch. Intern. Med., 167, 507-512. http://dx.doi.org/10.1001/archinte.167.5.507

Simon et al. (2008). Electronic health records: which practices have them, and how are clinicians using them? $J$. Eval. Clin. Pract., 14, 43-47. http://dx.doi.org/10.1111/j.1365-2753.2007.00787.x

Simpson, D. S., Nicholas, J., \& Cooper, K. D. (2001). The use of information technology in managing patients with coronary heart disease. Worcester: British Computer Society Primary Health Care Specialist Group.

Terry, A. L., Giles, G., Brown, J. B., Thind, A., \& Stewart, M. (2009). Adoption of electronic medical records in family practices: The provider's perspective. Fam. Med., 412, 48-52.

Thiru, K., de Lusignan, S., \& Hague, N. (1999). Have the completeness and accuracy of computer medical records in general practice improved in the last five years? The report of a two-practice pilot study. Health Inform. J., 5, 224-232. http://dx.doi.org/10.1177/146045829900500410

Thiru, K., Hassey, A., \& Sullivan, F. (2003). Systematic review of scope and quality of electronic patient record data in primary care. BMJ, 326. http://dx.doi.org/10.1136/bmj.326.7398.1070

Whitelaw, F. G., Nevin, S. L., Taylor, R. J., \& Watt, A. H. (1996). Morbidity and prescribing patterns for the middle-aged population of Scotland. Br. J. Gen. Pract., 46, 707-714.

\section{Copyrights}

Copyright for this article is retained by the author(s), with first publication rights granted to the journal.

This is an open-access article distributed under the terms and conditions of the Creative Commons Attribution license (http://creativecommons.org/licenses/by/3.0/). 